\title{
Pemanfaatan Generate Penjadwalan Sidang Pada PESSTA+ Berbasis Yii Framework Di Perguruan Tinggi
}

\author{
Indri Handayani $^{1}$ \\ Qurotul Aini ${ }^{2}$ \\ Priyatna Abdul Azis ${ }^{3}$ \\ Dosen STMIK Raharja, Mahasiswa STMIK Raharja \\ E-mail: indri.raharja.info ${ }^{1}$; aini.raharja.info ${ }^{2}$; priyatna@raharja.info ${ }^{3}$
}

\begin{abstract}
ABSTRAK
Dalam penyusunan jadwal sidang TA/Skripsi sering menjadi masalah, karena untuk sebuah penyusunan jadwal membutuhkan kompleksitas yang tinggi dan waktu yang cukup lama. namun untuk menyusun jadwal sidang TA/Skripsi harus mempertimbangkan beberapa komponen yang sinkron seperti waktu, hari, ruangan, dosen penguji, dan mahasiswa agar tidak bentrok satu sama lain. sistem generate penjadwalan sidang TA/Skripsi pada perguruan tinggi merupakan sebuah sistem informasi yang berbasis Yii Framework di mana sistem dapat mempermudah penjadwalan secara efektif dan efisien. dalam pembuatan sistem ini perancangan dan konsep nya melalui pengumpulan data dari proses penjadwalan di perguruan tinggi. hasil akhir dari penelitian ini berupa sebuah website di dalam sistem PESSTA+ yang mempermudah proses penjadwalan dan aplikasi penjadwalan nya berfungsi untuk mempercepat dan mempermudah penyampaian informasi jadwal sidang TA/Skripsi. dengan adanya validasi data mahasiswa, jadwal dosen, ruangan, waktu dan hari sehingga mempercepat proses penjadwalan sidang TA/Skripsi dan juga mempercepat kinerja dalam menyusun jadwal sidang.
\end{abstract}

Kata kunci-TA/Skripsi, PESSTA+, Sidang

\section{ABSTRACT}

In setting up a schedule of TA / Thesis hearings is often a problem, because to build a schedule that requires high complexity and long enough time. but to arrange the schedule of TA / Thesis trial should consider some synchronous components such as time, day, room, lecturer testers, and students so as not to clash with each other. the system produces scheduling TA / Thesis session at the college is an information system based Yii Framework in which the system can facilitate the scheduling effectively and efficiently. in making this system design and concept through completion of data from scheduling process in college. The end result of this research is a website in the PESSTA + system that is scheduling process and its scheduling application to accelerate and improve the delivery of schedule information TA / Thesis. with the validation of student data, schedule of lecturers, room, time and day so as to accelerate the process of scheduling TA / Thesis trial and also accelerate the performance in meeting the trial schedule.

Keywords-TA / Thesis, PESSTA +, Session

\section{PENDAHULUAN}

Sidang TA/Skripsi adalah sebuah tahapan akhir penentuan kelulusan bagi setiap mahasiswa pada sebuah perguruan tinggi. sejauh ini penyusunan jadwal sidang TA/Skripsi masih dikerjakan secara manual oleh sekretaris sidang maupun sekretaris jurusan. dengan 
penyusunan jadwal yang masih manual tersebut, kemungkinan kesalahan pada jadwal masih cukup tinggi tergantung ketelitian dan efisiensi penyusun jadwal pada saat periode sidang dengan peserta sidang yang cukup banyak. karena masih manual tentunya akan membutuhkan waktu tidak sedikit untuk koordinasi dalam penyusunan jadwal sidang.

Ada beberapa hal yang harus di perhatikan dalam penyusunan jadwal sidang yaitu diantaranya tidak boleh bentrok satu sama lain baik ruangan maupun waktu pelaksanaan sidang, kemudian apakah dosen penguji sudah sesuai dengan bidang keahlian TA/Skripsi yang akan disidangkan, dan sudah meratakah tugas dosen dalam menguji sidang TA/Skripsi. pada saat periode sidang dengan peserta yang tidak terlalu banyak, hal tersebut bisa terlaksana. Namun pada saat periode sidang dengan peserta yang banyak proses penyusunan jadwal sidang akan semakin rumit.

Adanya permasalahan tersebut, diperlukan sebuah sistem yang dapat mengoptimalkan jadwal sidang serta menghemat waktu penyusunan nya. dalam penyusunan jadwal sidang TA/Skripsi ini, optimalisasi penyusunan jadwal sidang menggunakan proses Generate. Generate and test merupakan metode yang paling sederhana dalam teknik pencarian heuristik, jika pembangkitan sebuah solusi yang mungkin (a possible solution) dikerjakan secara sistematis, maka prosedur ini menjamin akan menemukan solusi nya.

Permasalahan penjadwalan yang mengaitkan antara keinginan pribadi pekerja dengan ketersediaan jam kerja dalam organisasi dibahas dalam (Gunawan \& Toba 2016) mengusulkan agar setiap keinginan pribadi tersebut dijadikan sebagai hal yang dicari solusinya pada tahap terakhir dan jadwal saat verifikasi oleh tim dalam organisasi. konsep yang ditawarkan dalam (Gunawan \& Toba 2016) dengan membuat modul-modul yang terpisah antara pembangkitan jadwal awal, perbaikan under \& overstaffing dalam shift jam kerja, dan kemungkinan verifikasi keinginan pribadi dari pekerja. Hal tersebut dianggap cocok untuk dilakukan dalam konteks jadwal pekerja dalam organisasi dan julah pekerja cukup banyak karena dapat mengalokasikan jadwal pada pekerja lain. metode generate merupakan suatu sistem yang cocok untuk menyelesai kan masalah yang bersifat optimasi kombinatorial atau untuk kasus yang lebih kompleks lagi karena efisiensi dan fleksibilitasnya. penjadwalan sidang TA/Skripsi tersebut adalah permasalahan kombinatorial untuk mendapatkan jadwal sidang yang semestinya. metode generate dirasa tepat untuk menyelesaikan masalah penjadwalan tersebut secara lebih cepat dan tepat.

\section{PERMASALAHAN}

PESSTA (Penilaian Sidang Skripsi \& Tugas Akhir) adalah sebuah sistem informasi yang diciptakan dalam rangka memperlancar dan meningkat kan mutu pelaksanaan sidang tugas akhir/skripsi mahasiswa. Sistem PESSTA+ berfungsi untuk mempermudah proses penilaian tugas akhir/skripsi mahasiswa oleh pembimbing, pelaksanaan pengumpulan berkas laporan tugas akhir/skripsi oleh mahasiswa, proses pelaksanaan sidang tugas akhir/skripsi, penilaian sidang tugas akhir/skripsi oleh dewan penguji, pembuatan form perbaikan sidang, dan pembuatan berita acara hasil sidang. Melalui sistem PESSTA, maka pengumpulan laporan tugas akhir/skripsi, penilaian pembimbingan, pelaksanaan sidang, dan penilaian hasil sidang tugas akhir/skripsi pada perguruan tinggi raharja dapat dilakukan dengan efisien dan efektif.

Pada sistem PESSTA+ sudah ada sistem validasi jurnal, validasi hibah, validasi widuri, dan validasi sertifikat. Maka dari itu masih banyak sistem yang perlu di kembangkan dan diterapkan pada sistem PESSTA+, salah satunya sistem Auto Generate. Auto Generate merupakan sistem yang dapat mempermudah Sekretaris jurusan dalam penginputan jadwal sehingga tidak membuang waktu dalam membuat jadwal sidang sehingga lebih efektif dan efisien. Saat ini sistem Auto Generate pada PESSTA+ masih dalam tahap pengembangan dan belum dapat digunakan. 
Berdasarkan latar belakang yang telah diuraikan diatas maka terdapat 3 (tiga) hal yang dijadikan rumusan masalah antara lain:

1. Apakah cara kerja sistem penjadwalan sidang sudah baik saat ini?

2. Apakah sistem Auto Generate Penjadwalan Sidang dapat menyelesaikan masalah yang dialami saat ini ?

3. Bagaimana Sistem Auto Generate Sistem Penjadwalan Sidang tugas akhir/skripsi dapat di akses secara online?

Berdasarkan rumusan masalah diatas, dirasa sangat perlu untuk melakukan pengembangan pada sistem (Penjadwalan sidang Auto Generate) pada Perguruan Tinggi Raharja.

\section{METODOLOGI PENELITIAN}

Untuk membangun sistem generate penjadwalan sidang, metode penelitian yang digunakan meliputi Definisi masalah, Analisis kebutuhan, perencanaan, pembuatan protoype, implementasi, pengujian, dan pemeliharaan. berikut ini adalah rancangan metode penelitian yang digunakan :

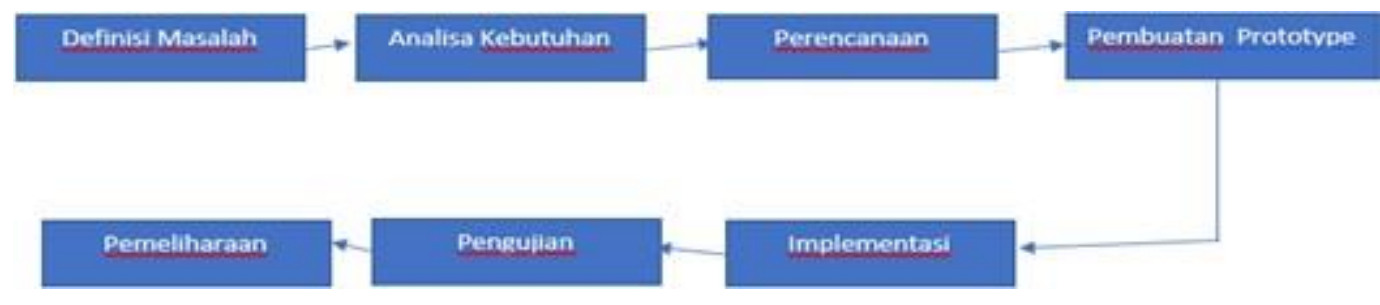

Gambar 1. Metode Penelitian

Keterangan :

1. Definisi Masalah, yaitu melakukan penelitian secara lebih detail agar dapat mengetahui alur letak permasalahan yang berjalan

2. Analisa Kebutuhan, yaitu setelah mengetahui letak permasalahan yang sudah di investigasi selanjutnya menganalisa kebutuhan apa saja yang akan digunakan.

3. Perencanaan, yaitu melakukan perencanaan terhadap sistem Pemanfaatan sistem generate penjadwalan sidang pada PESSTA+ berbasis YII framework.

4. Pembuatan Prototype, setelah rancangan terkonsep, langkah selanjutnya yaitu mengaplikasikannya dengan cara membuat prototype atau gambaran rencana mengenai sistem generate penjadwalan sidang pada PESSTA+ agar lebih mudah dipahami.

5. Implementasi, yaitu apabila tahapan-tahapan sebelumnya telah selesai dilakukan dan benar maka selanjutnya melakukan penerapan dari prototype yang telah dibuat pada sistem.

6. pengujian, pengujian dilakukan apabila telah selesai diimplementasikan pada sistem

7. Pemeliharaan, tahapan yang terakhir adalah pemeliharaan untuk merawat sistem yang telah berjalan dan diimplementasikan.

Berikut ini adalah daftar literature review yang digunakan dalam penelitian ini : 
1. Penelitian yang di lakukan oleh Haiyan Wang dan Xiao SanSong (2015) yang berjudul "Research on BIM Contstruction Schedule Generating Algorithm" Penelitian ini tentang mengusulkan jadwal pembuatan skema secara otomatis berdasarkan integrasi aturan IFC dan Algoritma GA Adaptif. Kemudian desain algoritma GA berdasarkan fungsi seleksi trigonometri operator, sesuai dengan matriks yang dihasilkan. Dalam proses penjadwalan otomatis bisa menggunakan ontologi untuk menambah kendala antar komponen guna meningkatkan kelayakan generasi otomatis penjadwalan.

2. Penelitian yang dilakukan oleh Guoquan Liu, Yifeng Zeng, Dong Li, Yingke Chen (2015) yang berjudul "Schedule Lengt and Reliability-Oriented-Multi-Objective scheduling for Distributed Computing" penelitian ini tentang memaksimalkan keandalan sistem dan meminimalkan panjang jadwal adalah dua tujuan utama dalam menjadwalkan sistem komputasi terdistribusi. Kedua tujuan ini telah dipertimbangkan secara terpisah oleh kebanyakan peneliti walaupun secara lebih realistis mereka harus dipertimbangkan secara bersamaan. Hasil percobaan menunjukkan bahwa percobaan untuk masalah ini gangguan lateral tidak berpengaruh terhadap jumlah solusi yang tidak didominasi, terlepas dari metode yang perhitungan yang digunakan untuk menentukan antara jarak dan solusi.

3. Penelitian yang dilakukan oleh Mohammad Al-Haj Hassan dan Osama Al HajHassan (2016) yang berjudul "Constraint Aware and User Friendly Exam Scheduling System" Penelitian ini tentang kendala yang harus diperhitungkan dalam penjadwalan. Penjadwalan ujian adalah kunci penting untuk sekolah dan universitas secara teratur agar periode ujian menjadi lancar. Dalam hal ini, kami menyajikan sistem penjadwalan ujian yang menggunakan penjadwalan grafik teknik. Kami fokus pada dua aspek. Pertama kendala yang dihadapi sistem. Kedua, user friendly interface dari system.

4. Penelian yang dilakukan oleh Venkat Rohini dan A.M Natarajan (2016) yang berjudul "Comparism of Genetic Algorithm with particle Swarm Optimisation, Ant Colony Optimisation and Tabu Search Based on University Course Scheduling System" Penelitian ini tentang menemukan metode yang sesuai untuk memecahkan masalah penjadwalan mata kuliah universitas. Makalah ini membandingkan penggunaan Particle Swarm Optimization (PSO), Ant Colony Optimization (ACO), Tabu Search and Genetic Algorithm (GA) dalam persiapan sistem penjadwalan mata kuliah universitas. Kendala berat tertentu, yang harus terpenuhi dan beberapa kendala batasan yang harus dipenuhi dan dipertimbangkan. Algoritma harus memeriksa kepuasan dari batasan keras dan kemungkinan untuk memenuhi batasan lunak.

5. Penelitian yang dilakukan oleh "Ruey Maw Chen, dan Hsiao Fang Shih (2013)" Penelitian ini tentang masalah jadwal mata kuliah studi yang dipelajari melibatkan kendala seperti kelas, kurikulum kelas dan variable lainnya. Serentak, beberapa 
batasan lunak juga perlu dipertimbangkan, termasuk waktu yang disukai dosen, waktu kelas favorit dll. Preferensi ini sesuai dengan nilai kepuasan yang diperoleh melalui kuesioner. Partikel Swarm Optimization (PSO) adalah skema yang menjanjikan untuk memecahkan masalah NP-Complete karena konvergensinya yang cepat. Oleh karena itu PSO diterapkan untuk memecahkan masalah timetabling course dalam pekerjaan ini. Untuk mengurangi kompleksitas, komputasi, timeslot dirancang dalam pengkodean partikel sebagai unit penjadwalan.

6. Penelitian yang dilakukan oleh I Made Budi Adnyana (2017) yang berjudul "Perancangan Sistem Penjadwalan Assisten Dosen Menggunakan Algoritma Genetika" penelitian ini membahas tentang Permasalahan Assisten dosen dalam melaksanakan perkuliahan karena penjadwalan nya masih dalam tahap manual. dan kesediaan jam mengajar menjadikan proses penjadwalan asdos menjadi semakin kompleks dan memakan waktu yang relative lama untuk penyusunannya. maka diusulkan untuk membuat sebuah rancangan sistem penjadwalan assisten dosen menggunakan algoritma Genetika. Sistem penjadwalan assisten dosen ini telah berhasil dirancang dengan beberapa tahap, dimulai dari pendefinisian aturan jadwal assisten dosen di STIKOM Bali, Representasi Kromosom, Perancangan Fitness Function dan Stopping criteria, serta perancangan perangkat lunak menggunakan diagram UML.

Setelah melakukan peninjauan terhadap Literature Review yang ada, telah banyak penelitian mengenai sistem yang berhubungan dengan generate penjadwalan sidang. karena pada sistem PESSTA+ belum diterapkan sistem Generate Penjadwalan Sidang yang memudahkan sekretaris sidang dalam penginputan jadwal dan menyusun jadwal sidang. Karena itu penulis membahas hal "Pemanfaatan Sistem Generate Penjadwalan Sidang pada PESSTA+ berbasis Yii Framework di Perguruan Tinggi" agar dapat memudahkan sekretaris jurusan dalam penginputan dan penyusunan jadwal sidang.

\section{HASIL DAN PEMBAHASAN}

PESSTA+ merupakan salah satu official site online yang dimiliki oleh Perguruan Tinggi Raharja yang dapat memberikan informasi mengenai 10 penilaian objektif sidang kapan pun dan di mana pun . Karena keterbatasan fitur dan sistem yang ada di PESSTA+ belum ada fitur yang dinamakan sistem generate penjadwalan sidang di dalam PESSTA+, karena sistem tersebut masih lokal dan belum dapat di akses secara online. maka dari itu dibuatlah sistem dan fitur mengenai sistem generate penjadwalan sidang pada PESSTA+. 


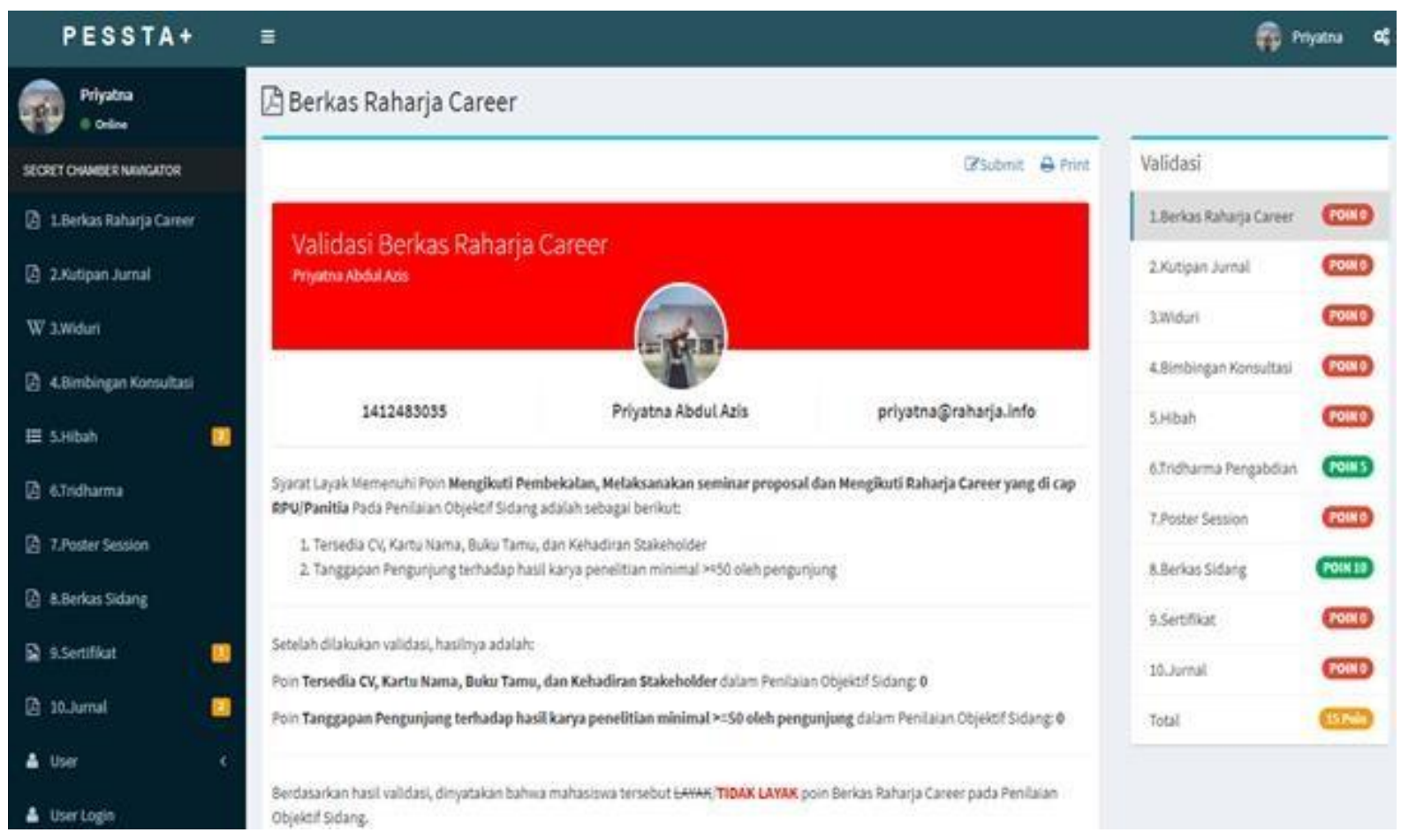

Gambar 2. Halaman Validasi PESSTA+

Dengan adanya permasalahan tersebut dalam memberikan informasi, maka rumusan masalah dalam penelitian ini adalah bagaimana cara merancang sebuah sistem informasi yang dapat memudahkan dalam menyusun dan menginput jadwal sidang pada sistem PESSTA+ dapat di akses secara online pada Perguruan Tinggi Raharja.

\subsection{Pemecahan Masalah}

Sebagai salah satu solusi atau alternatif pemecahan masalahnya adalah dengan merancang, membangun, dan menyediakan suatu sistem informasi berbasis Yii Framework serta mampu mempermudah proses sekretaris sidang mendapatkan informasi yang berhubungan dengan kegiatan TA/Skripsi dan mampu menyusun dan menginput jadwal secara lebih efektif dan efisien serta sistem yang lebih mudah di kembangkan dan dimaintenance.

\subsection{Listing Program}




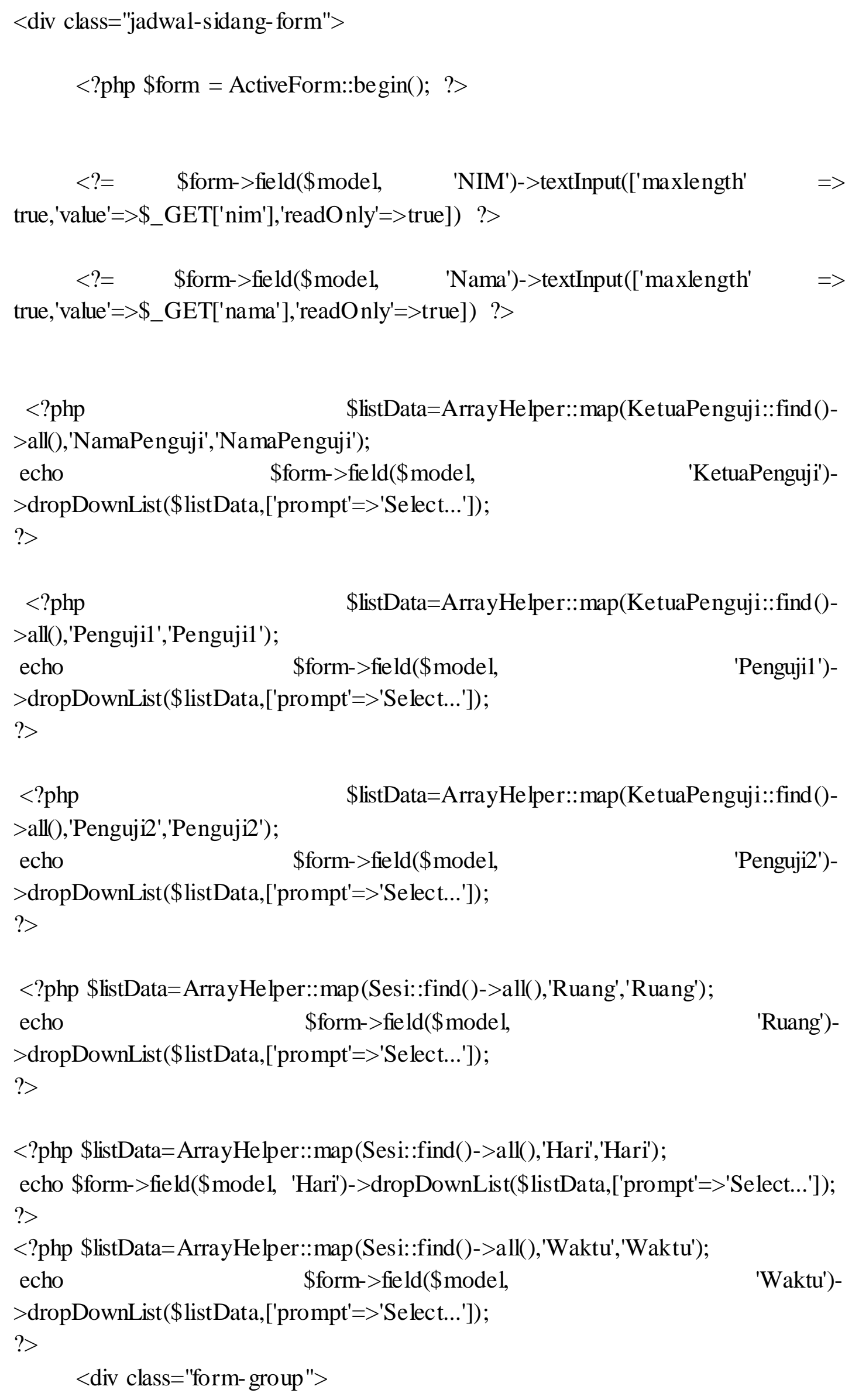


$<$ ? = Html::submitButton(\$model->isNewRecord ? 'Create' : 'Update', ['class' $=>$ \$model->isNewRecord ? 'btn btn-success' : 'btn btn-primary']) ?> $</$ div $>$

$<$ ?php ActiveForm::end(); ?> 


\subsection{Implementasi}

Generate jadwal sidang yang telah dibuat akan diimplementasikan di dalam sistem PESSTA+ sebagai sarana mempermudah dalam memberikan informasi dan akses terhadap sekretaris sidang dalam menginput jadwal sidang

Berikut cara mengimplementasikan Generate jadwal sidang pada PESSTA+ :

1. Buka aplikasi pengolah code (IDE), dalam kasus ini saya menggunakan Codeanywhere.

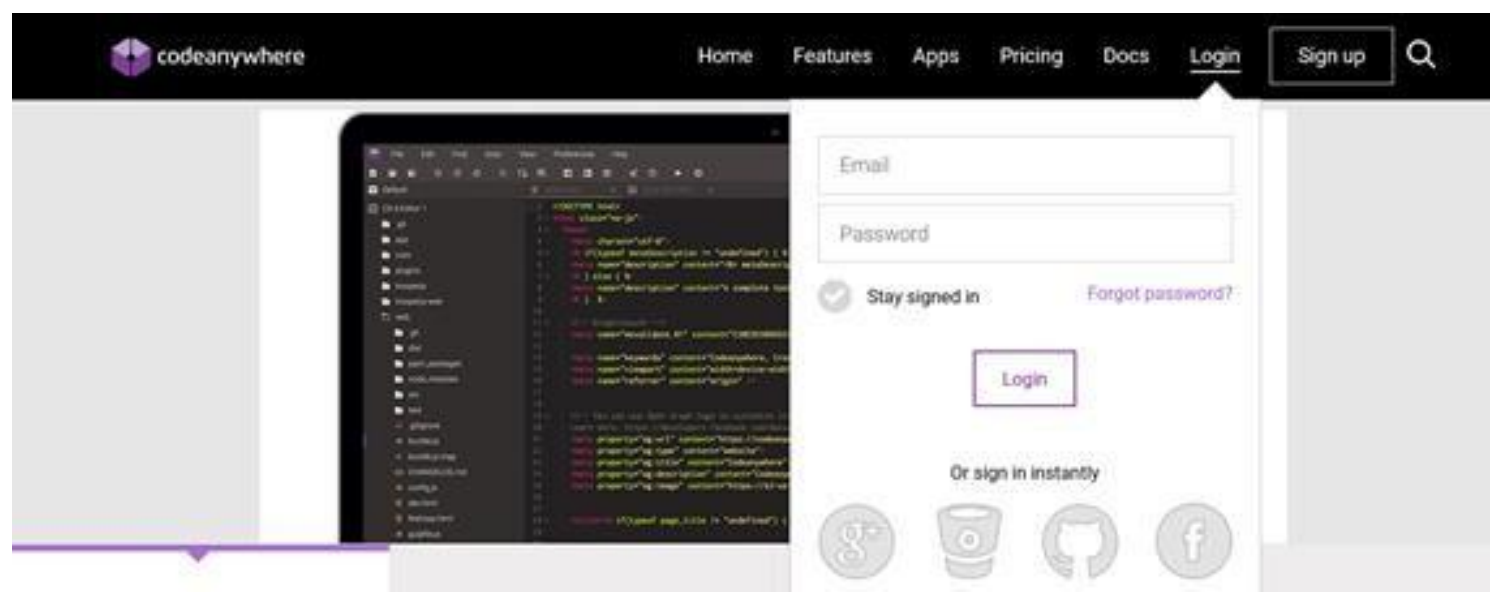

Gambar 3. Tampilan awal login Codeanywhere

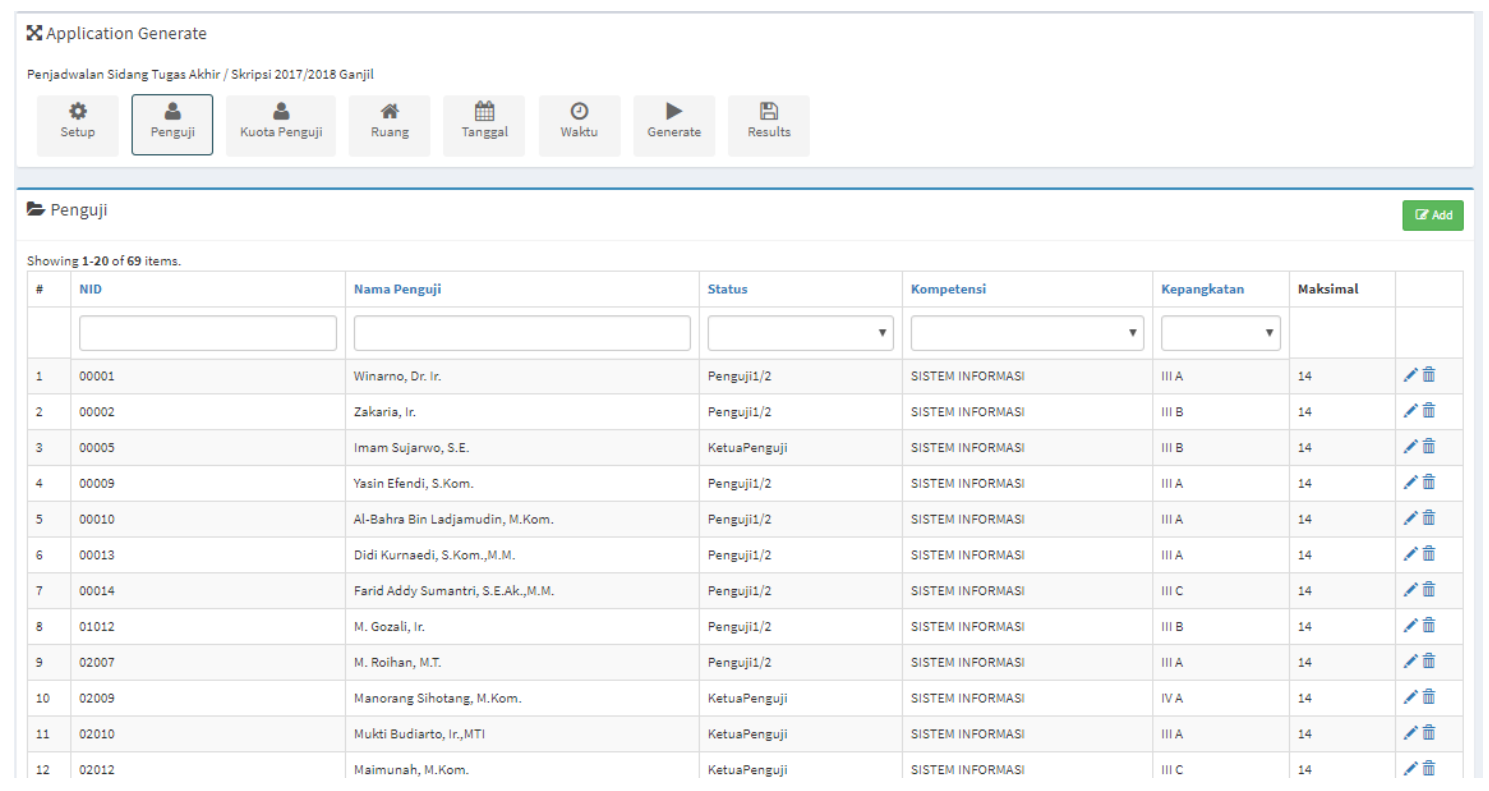

Gambar 4. Tampilan Keseluruhan Dosen Penguji 
X Application Generate

Penjadwalan Sidang Tugas Akhir/Skripsi 2017/2018 Ganjil

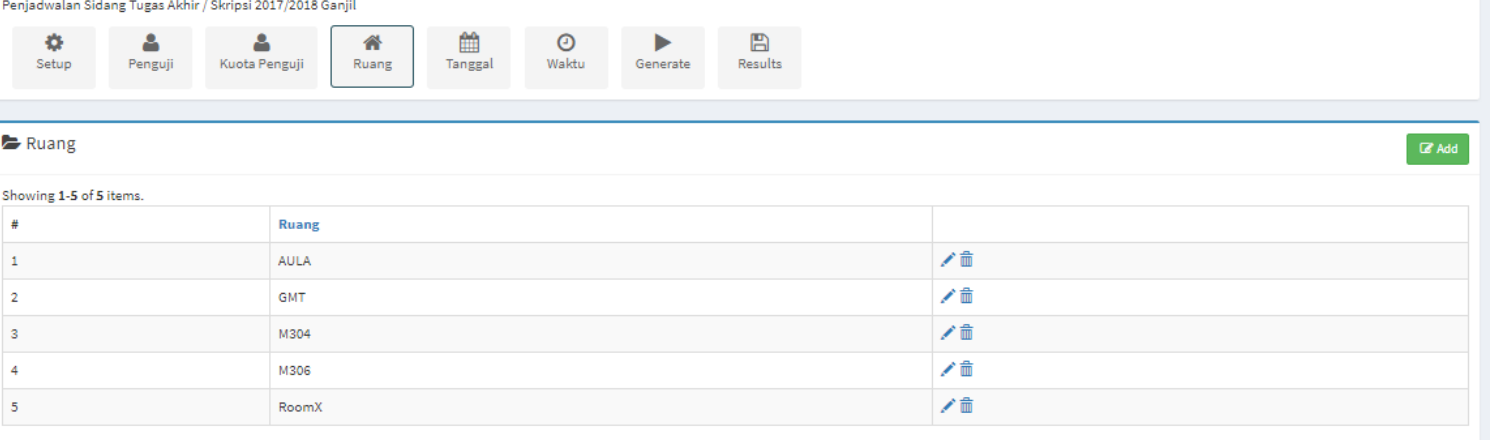

Gambar 5. Tampilan Halaman Ruang

XApplication Generate

Penjadwalan Sidang Tugas Akhir/ Skripsi 2017/2018 Ganjil

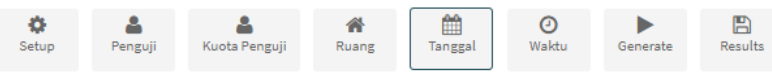

E Tanggal

Showing 1.7 of 7 items.

\# Tanggal

$12018-02-26$

2 2018.02-27

2018-02-23

5

6 2018-03-05

$7 \quad 2018-03-0$

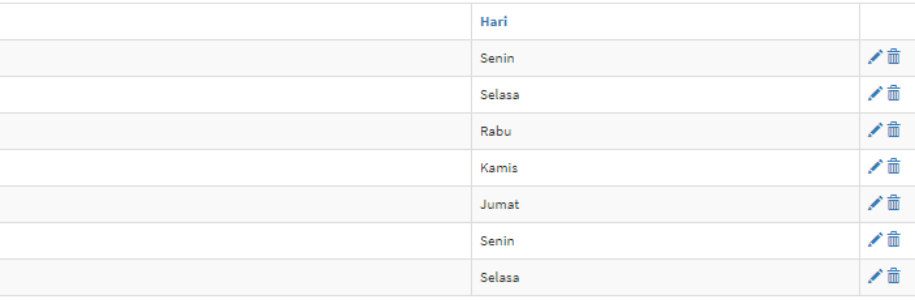

Gambar 6. Tampilan Halaman Tanggal

\section{Application Generate}

Penjadwalan Sidang Tugas Akhir/ Skripsi $2017 / 2018$ Ganjj

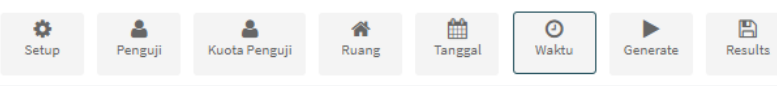

E Waktu

Showing 1-8 of 8 items.

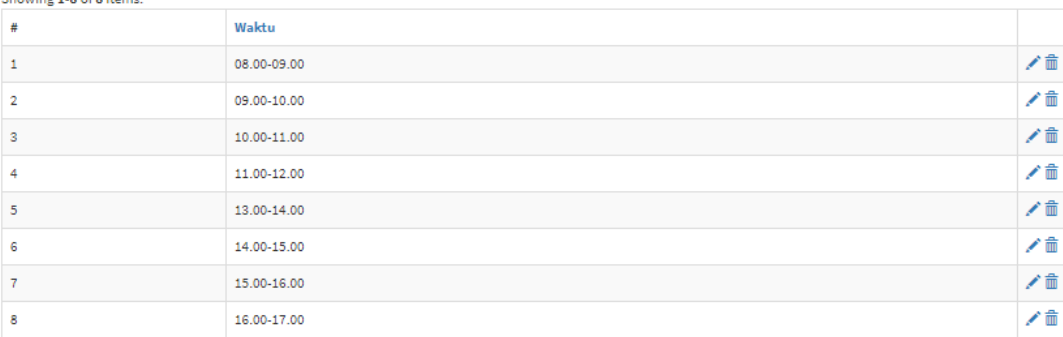

Gambar 7. Tampilan Halaman Waktu 


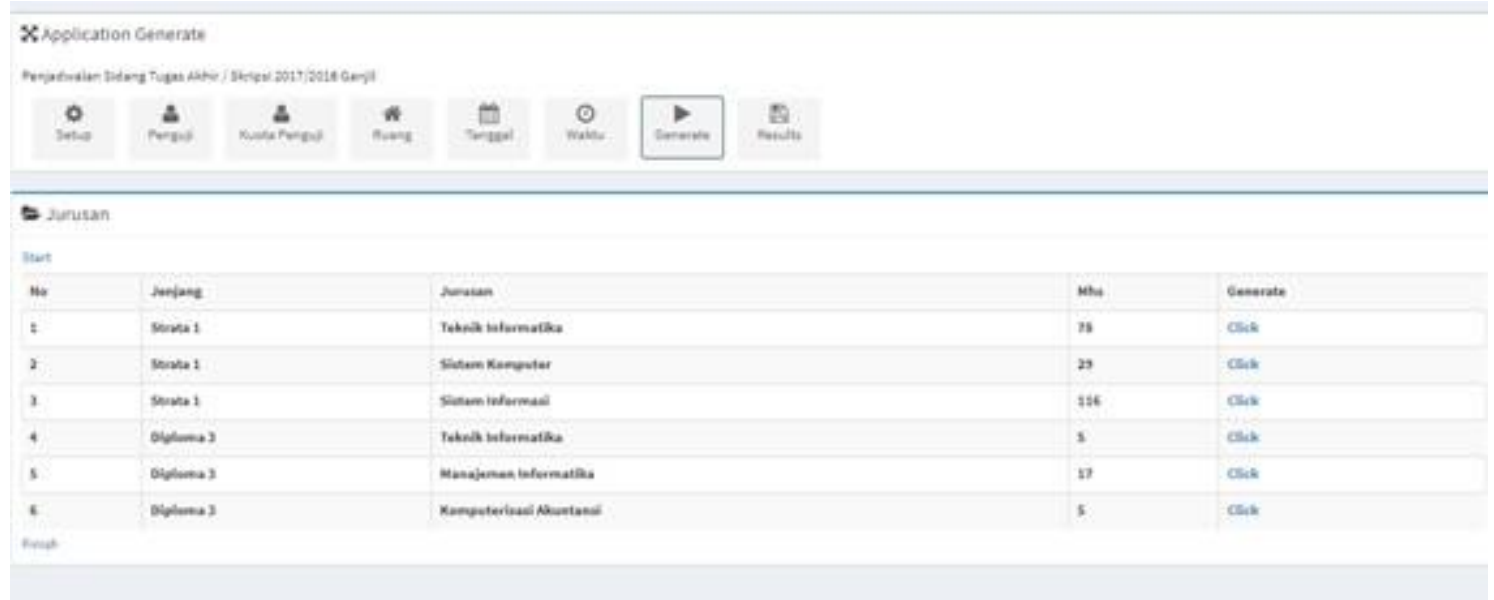

Gambar 8. Tampilan Halaman Generate Jadwal Sidang

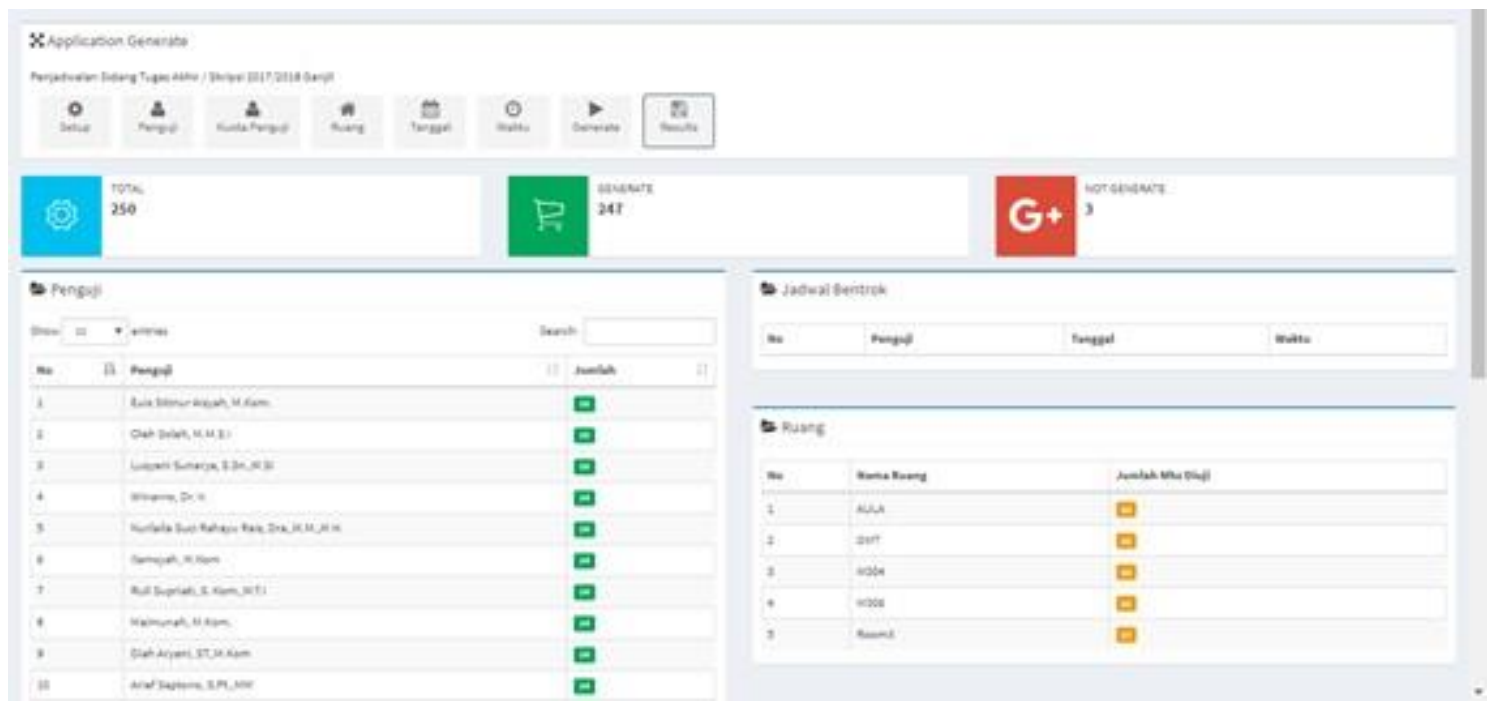

Gambar 9. Tampilan Hasil Result Generate Jadwal Sidang

\section{KESIMPULAN}

Kesimpulan dari sistem yang telah dibuat dan telah sesuai dengan apa yang ingin ditampilkan, dapat ditarik kesimpulan bahwa dengan adanya generate jadwal sidang pada PESSTA+ dapat memberikan kemudahan yang efektif dan efisien karena;

1. Menciptakan sistem informasi Sistem Penjadwalan Auto Generate yang dapat berjalan secara efektif dan efisien serta memberikan informasi yang akurat sehingga informasi tersebut dapat bermanfaat bagi admin PESSTA+ terutama pada bagian Penjadwalan Auto Generate.

2. Sistem yang akan dibuat lebih informatif dan sehingga dapat memudahkan admin dan dosen pengjuji dalam membaca informasi mengenai data yang ada pada Auto Generate PESSTA+ 
3. Sistem proses penyusunan jadwal sidang yang sebelumnya dibuat secara manual, dimana panitia sidang membuat jadwal sidang dengan menginputkan variabel yang berkaitan dengan data sidang yaitu seperti Mahasiswa, Penguji, Ruang, dan Waktu secara manual. Saat ini di sistem Generate Jadwal Sidang pada PESSTA+ yang bertujuan untuk mempermudah panitia sidang dalam membuat jadwal sidang secara terkomputerisasi.

\section{SARAN}

Untuk meningkatkan sistem generate jadwal sidang pada PESSTA+ di perguruan tinggi penulis memberikan 3 (tiga) saran yaitu :

1. Dapat terpenuhi nya kebutuhan khususnya sekretaris sidang akan pelayanan kampus yang optimal. untuk meningkat kan kualitas pelayanan kampus sebaiknya digunakan sistem yang terkomputerisasi yang mempunyai daya akses yang cepat dan akurat sehingga lebih efektif dalam segi waktu. dan agar dapat dilakukan pengembangan dan perbaikan secara berkesinambungan pada penelitian berikutnya.

2. perlu adanya penambahan informasi di sistem generate penjadwalan sidang pada PESSTA+ sehingga memungkinkan tidak adanya lagi jadwal, ruang, dan waktu yang bentrok.

3. dilakukan nya pengembangan sistem PESSTA+ dalam hal sistem generate jadwal sidang agar tercapainya target dalam memberikan informasi yang akurat

\section{DAFTAR PUSTAKA}

[1] Wang, H., \& Song, X. (2015). Research on BIM Construction Schedule Generating Algorithm. International Journal of Simulation--Systems, Science \& Technology, 16.

[2] Liu, G., Zeng, Y., Li, D., \& Chen, Y. (2015). Schedule length and reliability-oriented multi-objective scheduling for distributed computing. Soft Computing, 19(6), 1727-1737.

[3] Hassan, M. A. H., \& Hassan, O. A. H. (2016). Constraints aware and user friendly exam scheduling system. Int. Arab J. Inf. Technol., 13(1A), 156-162.

[4] Rohini, V., \& Natarajan, A. M. (2016). Comparison of genetic algorithm with particle swarm optimisation, ant colony optimisation and tabu search based on university course scheduling system. Indian Journal of Science and Technology, 9(21).

[5] Chen, R. M., \& Shih, H. F. (2013). Solving university course timetabling problems using constriction particle swarm optimization with local search. Algorithms, 6(2), 227-244.

[6] Kosasi, Sandi (2017). EVALUASI PENGGUNAAN TEKNOLOGI MEDIA SOSIAL DALAM MEMPERLUAS BISNIS PEMASARAN ONLINE. STMIK Pontianak. 
[7] Adnyana, I. M. B. (2017). Perancangan Sistem Penjadwalan Asisten Dosen Menggunakan Algoritma Genetika (Studi Kasus: STIKOM Bali). E-Proceedings KNS\&I STIKOM Bali, 569-574.

[8] Gunawan, C. A., \& Toba, H. (2016). Pembangkitan Solusi Penjadwalan Berprioritas Melalui Penerapan Constraint Satisfaction Problem (Studi Studi Kasus: Laboratorium Fakultas Teknologi Informasi Universitas XXX ). Jurnal Teknik Informatika Dan Sistem Informasi, 2(April), 43-52. 